\title{
É possível trabalhar o conflito como matéria-prima da gestão em saúde?
}

\author{
Can conflict be used as the "raw material" \\ for health services management?
}

\footnotetext{
1 Faculdade de Ciências Médicas, Universidade Estadual de Campinas, Campinas, Brasil.

Correspondência L. C. O. Cecílio Departamento de Medicina Preventiva e Social, Faculdade de Ciências Médicas, Universidade Estadual de Campinas. C. P. 6111, Campinas, $S P$ 13083-970, Brasil. cecilioluiz@uol.com.br
}

\begin{abstract}
The author examines the possibility of understanding ordinary conflicts within health care organizations as a management object. He thus proposes the use of an "analytical matrix" aimed at allowing the actors involved in conflictive situations (always in a self-analytical position) to achieve a broader understanding of such conflicts. There would be new possibilities for contractibility in the management of the health service's daily routine, as well as new shapes in the relations among workers; this would include bringing previously concealed conflicts to the surface and helping them reach the service's decision-making arena. The author also indicates possible difficulties for adopting this type of managerial practice.
\end{abstract}

Conflict (Psychology); Organizations; Management

\section{O conflito na teoria das organizações}

As agendas de trabalho dos gerentes das organizações de saúde são sempre invadidas, no diaa-dia, por um conjunto de fatos que podem ser designados como conflitos. Na verdade, "lidar com conflitos" é uma constante no cotidiano dos gerentes e da direção superior, em toda e qualquer organização.

Pretendemos, neste artigo, fazer dois movimentos sucessivos e complementares. Primeiro, adotar uma definição de conflito a partir da revisão de um certo debate, ainda que não exaustivo, sobre o tema existente na literatura. Depois, a partir dessa conceituação de caráter abstrato, sugerir uma formatação mais operacional de um “dispositivo de gestão" (a planilha de análise de conflitos) que permita uma eventual apropriação do conceito e sua aplicação em situações reais por parte de coletivos nos serviços de saúde. Tal movimento da teoria em direção à prática tem a pretensão, em última instância, de contribuir para processos de gestão, nos quais os trabalhadores poderiam alcançar uma maior competência para reconstruir suas práticas e relações cotidianas. O artigo pode ser visto como um exercício de especulação sobre novas possibilidades gerenciais, tendo como ponto de partida um tema tão comum em todas as organizações: o conflito. Sem ter o caráter de investigação empírica mais aprofundada, apóia-se na experiência do autor que teve a 
oportunidade de testar a aplicabilidade do instrumento proposto em várias situações institucionais.

Motta 1, fazendo uma revisão na literatura, afirma haver três grandes correntes na abordagem do conflito na organização. A primeira entende os conflitos como o resultado de disputa de interesses inconciliáveis inscritos na estrutura social e que invadem a organização. A segunda corrente veria o conflito como algo envolvendo papéis em nível organizacional, resultantes da evolução tecnológica e econômica que imporia adaptações à organização da produção e, como conseqüência, uma crescente necessidade de controle dos gerentes sobre a coletividade de trabalhadores. Finalmente, uma terceira corrente, que trataria o conflito como sendo essencialmente de personalidade e de percepções em nível individual, ou seja, uma discrepância entre aspirações individuais e imposições organizacionais. Afinal, o autor advoga uma posição eclética que reconhece que "interesses de classe, como os do trabalho, por exemplo, não destroem interesses individuais e de pequenos grupos, que continuam a gerar conflitos $e$ precisam ser enfrentados pela gerência" 1 (p. 154).

Burrell \& Morgan (1979, apud Hall 2) defendem que haveria três visões sobre interesses, conflito e poder. Na visão unitária, conforme definição dos autores, o conflito poderia ser visto como um fenômeno raro e transitório que poderia ser eliminado através da ação gerencial apropriada. Seriam sempre conflitos interpessoais e causados por funcionários problemáticos ou criadores de caso. Uma segunda visão, a pluralista, encara o conflito como uma característica intrínseca e inerradicável dos assuntos organizacionais e enfatiza seus aspectos potencialmente positivos e funcionais. Por fim, uma terceira visão, denominada como radical pelos autores, "encara o conflito como força motora onipresente e causadora de rupturas, que impele às mudanças na sociedade em geral e nas organizações em particular. Reconhecem que o conflito pode ser um aspecto reprimido do sistema social, nem sempre visível no nível empírico como 'realidade"' 2 (p. 93).

Outro autor que tenta elaborar uma definição de conflito mais abrangente é Lukes 3, ao afirmar que, para além dos conflitos abertos, observáveis, comportamentais, é preciso reconhecer que há certos conflitos que não alcançam a agenda formal da direção e das gerências. Circulam pelos corredores, pelas áreas de bastidores, como um murmúrio institucional, os conflitos encobertos. Há ruídos, sim, mas esses não têm força para impor-se à agenda da direção. “Todas as formas de organização política têm preconceitos em favor da exploração de algumas espécies de conflito e a supressão de outras, porque a organização é a mobilização do preconceito. Algumas discussões são organizadas dentro da política e outras fora dela" 3 (p. 13). Um exemplo: as insatisfações do pessoal de enfermagem em relação a certos privilégios que os médicos têm no hospital (flexibilidade de horário, grande autonomia nas suas práticas, desconsideração com o trabalho da enfermagem etc.). Diz-se que esses conflitos são encobertos porque não conseguem penetrar a agenda da direção, serem apreciados e resultarem em alguma forma de modificação do status quo. Os conflitos encobertos são os ruídos que a direção não escuta, nem pode, de alguma forma, escutar: fazer isso seria ter que enfrentar relações de poder instituído, com grande poder de reprodução/manutenção. Assim, a não tomada de decisão (em relação à situação conflituosa) seria um meio pelo qual as demandas de mudanças nas atuais relações de poder seriam sufocadas antes mesmo de serem enunciadas ou mantidas encobertas ou eliminadas antes mesmo de ganharem acesso à arena de tomada de decisões. Lukes afirma, ainda, que haveria um terceiro tipo de conflito, que ele denomina de latente. Seriam conflitos que poderiam manifestar-se desde que determinados atores pudessem tomar consciência do quanto seus verdadeiros interesses são desconsiderados. Aqui, Lukes amplia a clássica definição de poder - que diz que "A tem poder quando faz B fazer algo que não faria se não fosse A" - para a idéia de que "A também exerce poder sobre $B$ ao influenciar, moldar ou determinar seus próprios desejos. Com efeito, não é o supremo exercício do poder levar outro, ou outros, a ter desejos que se que queria que tivessem - isto é, assegurar sua obediência, controlando seus pensamentos e desejos?" 3 (p. 18). Estamos, com essa visão, em pleno campo da ideologia, da falsa consciência, da concepção gramsciana de hegemonia política e cultural de um grupo social sobre os subalternos, de forma que os excluídos ou os submetidos às várias formas de violência e dominação sequer chegam a estar conscientes dos seus interesses. O que Lukes 3 quer enfatizar é que pode haver relações de poder que não se expressam, necessariamente, em conflitos observáveis ou mesmo encobertos, na medida em que os interesses dos dife- 
rentes atores nem sempre seriam conscientemente articulados e observáveis.

\section{Delimitando um conceito de conflito}

A discussão sobre conflito, tanto no plano social mais geral como em nível das organizações, é extensa, e não pretendemos tomar essa discussão como o centro do presente artigo. A revisão cuidadosa que Birnbaum 4 faz sobre o tema, a partir de uma leitura sociológica, é uma referência. O que nos propomos, aqui, é adotar uma definição de conflito que permita sua utilização no contexto da gestão de serviços de saúde. Ou, pelo menos, como o título do artigo sugere, nos indagarmos se o conflito, conceito tão prenhe de sentidos, pode ser apreendido como "matéria-prima da gestão em saúde". A primeira definição que adotamos, ela mesma podendo ser problematizada conforme o referencial teórico adotado pelo leitor, é a de que "o conflito é sempre consciente", como advoga Boudon 5. Consideramos, ainda, que a eclosão e o desenvolvimento do conflito podem ser explicados tanto a partir das posições detidas nas "estruturas" como de intencionalidades opostas dos atores que ocupam esses papéis, uma vez que só eles podem decidir-se por agir e transformar o conflito, que até lá permanece potencial, num confronto real. Pensamos, também, que há conflito quando dois ou mais atores fazem uma apreciação situacional divergente - situação entendida no estrito sentido proposto por Matus 6: o recorte interessado da "realidade" feito por um ator engajado na ação. Essa definição está comprometida com duas idéias principais. A primeira é a de que cada ator faz uma apreciação da "realidade" que depende do lugar que ocupa na organização que está sendo analisada. Seu lugar na "estrutura". O olhar condicionado pelo lugar. A segunda idéia é a de que esse olhar é, sempre e antes de qualquer coisa, um olhar comprometido com a ação, com intencionalidades. Fiquemos, então, com a idéia de que há, no cotidiano das organizações, uma incontornável diferença entre esses modos de olhar dos distintos atores, sempre engajados com a ação. Nesse sentido, estamos de acordo com Boudon, em obra citada por Friedberg 7, quando afirma que a racionalidade da ação dos atores institucionais seria produto conjunto de um efeito de posição (que dependeria da posição que um decisor ou ator ocupa num contexto determinado e que condiciona seu acesso a informações pertinentes) e de um efeito de disposição (que dependeria das disposições mentais, cognitivas e afetivas desse mesmo ator, e que são sempre, em parte, pré-formadas por uma socialização passada). A “organização" que o diretor do hospital ou do centro de saúde vê não é a mesma que o funcionário da recepção ou a enfermeira do bloco obstétrico vê. Trabalhamos ainda com a idéia de que essas diferenças são parte das tensões constitutivas de toda e qualquer organização e explicam, em boa medida, os conflitos que invadem as agendas dos seus gerentes 8 .

Vamos adotar, ainda, a idéia de que conflito é fenômeno, é comportamento, é ruído: SUPERFÍCIE. As tensões constitutivas seriam a ESPESSURA, a "estrutura”, os "lugares" (instâncias, topos, saberes/poderes das diferentes corporações etc.) instituídos. Estrutura e superfície, tensões constitutivas e conflitos se interpenetrando, produzindo deslocamentos, instituindo novas configurações da organização, mas também reproduzindo, confirmando instituídos, malhas de captura: territórios de poder. Aqui, filiamo-nos às contribuições feitas pela sócio-análise francesa, em particular nas formulações contidas nos trabalhos já clássicos de Lapassade \& Lourau 9 e Lapassade 10, em particular a crítica que fazem aos teóricos organizacionais, no sentido de que suas análises teriam se desenvolvido com o esquecimento ou subestimação da instituição, termo que designa a produção e a reprodução das relações sociais dominantes, tanto nos pequenos grupos como na estrutura das organizações.

Podemos então dizer que conflito é o que escapa, o que se apresenta, o que denuncia, o que invade a agenda de quem faz a gestão, o que incomoda. São os comportamentos observáveis que exigem "tomadas de providências": a briga entre funcionários, o bate-boca de pacientes com funcionários, a disputa de recursos entre unidades diferentes, as reclamações de pacientes. Ruídos. Os conflitos abertos, tal qual definidos por Lukes 3. Mas tomaremos, também, potencialmente, como objeto da ação gerencial, os conflitos encobertos, aqueles que ainda circulam nos bastidores, na "rádio-corredor" e que não conseguem, nos sistemas de gestão mais tradicionais, ocupar a agenda da direção. Trataremos, então, como conflitos, os fenômenos, os fatos, os comportamentos que, na vida organizacional, constituem-se em "ruídos" e são reconhecidos como tais pelos trabalhadores e pela gerência.

Nas reflexões que pretendemos fazer neste texto, tomaremos como foco de atenção os conflitos abertos e os encobertos, trabalhando com a idéia de que estes últimos poderão vir a ser tratados na agenda da direção em função do quanto se criem dispositivos de gestão mais 
publicizados e com mais sensibilidade para escutar e processar os conflitos encobertos que, em sistemas de gestão mais fechados, acabam circulando pela "rádio-corredor" da organização. Pensamos que os gerentes e os trabalhadores de saúde podem ser pensados como homens da ação, como seres práticos, com capacidade para conhecer e (re)criar a realidade humana, inclusive tomando uma postura ativa e criadora diante dos conflitos.

A definição de conflito que adotamos coincide, então, com a visão pluralista do esquema de Burrell \& Morgan, isto é, aquela que considera os conflitos como característica intrínseca e inerradicável da vida organizacional, da mesma forma que toma emprestados os conceitos de conflitos abertos e encobertos de Lukes e assume a postura eclética de Motta, que defende que há uma convivência, sem exclusão, de conflitos decorrentes de interesses de classe ou de lugares diferenciados na estrutura social com aqueles ligados ao trabalho e à disputa de interesse entre pequenos grupos e mesmo conflitos interpessoais.

A pergunta que estrutura as reflexões deste texto é se seria possível instrumentalizar os gerentes e os coletivos das organizações de saúde com determinados dispositivos que lhes permitam tomar os conflitos como tema da gestão, capacitando-os a compreender o que os conflitos estão dizendo, denunciando, em última instância, contribuindo para mudanças substantivas no cotidiano das organizações, em particular na relação entre os trabalhadores e entre estes e os usuários. No limite, possibilitar que conflitos encobertos acessem a agenda de decisão, superando crônicas situações de injustiça a que são submetidos tanto os trabalhadores como os usuários.

\section{Uma "matriz de análise dos conflitos" como ferramenta gerencial}

A elaboração de uma "matriz de análise dos conflitos" teria a pretensão de facilitar a análise, por coletivos de trabalhadores, desse fenômeno corriqueiro nas organizações que são os conflitos. Inicia com o reconhecimento e enunciação dos conflitos mais freqüentes vividos por determinados coletivos ou percebidos por determinadas instâncias de direção para, na seqüência, fazer uma priorização dos conflitos a serem analisados. A matriz tem o formato apresentado na Figura 1. É bom que se esclareça que o formato dessa planilha é apenas uma sugestão de possibilidade de organização da discussão (um roteiro de discussão), podendo ser modificada, recriada em cada contexto organizacional distinto, servindo, ainda, como um "guia para a reflexão" de grupos organizacionais.

Na coluna 1, enuncia-se o conflito em análise. Na coluna 2, tenta-se fazer um movimento que vai da SUPERFÍCIE em direção à ESPESSURA, buscando-se caracterizar as tensões constitutivas do conflito. Para tanto, introduzem-se os seguintes conceitos: (a) os atores envolvidos no conflito; (b) a apreciação que fazem da situação conflituosa a partir do lugar que ocupam e de seus interesses específicos; (c) como os atores jogam no contexto do conflito (São mais ofensivos ou defensivos? Jogam por omissão? Aliamse a outros atores? Quais?); (d) quais os recursos que os atores envolvidos controlam e que têm importância para a situação conflituosa especificamente? Na coluna 3, propõe-se que o coletivo explicite como o conflito analisado tem sido trabalhado (fica de fora da pauta da direção ou tem sido tema de disputa? É simplesmente ignorado, "jogado para debaixo do tapete ou, simplesmente, "incorporado à paisagem”). Finalmente, na coluna 4, a partir da compreensão que o grupo conseguir alcançar, são pensadas novas possibilidades de se trabalharem os conflitos, de forma mais pública e acordada, dentro dos limites de governabilidade do grupo.

\section{Um exemplo de utilização da matriz para análise de conflitos freqüentes nas organizações de saúde}

Para uma melhor compreensão, pelo leitor, da utilização potencial da matriz de análise de conflitos, apresentamos sua utilização e discussão em uma situação hipotética, mas bas-

\begin{tabular}{|l|l|l|l|}
\hline $\begin{array}{l}1 \text { - Conflito em } \\
\text { análise }\end{array}$ & $\begin{array}{l}2 \text { - Tensões constitutivas } \\
\text { do conflito }\end{array}$ & $\begin{array}{l}3 \text { - Como se lida com } \\
0 \text { conflito atualmente }\end{array}$ & $\begin{array}{l}4 \text { - Novas possibilidades } \\
\text { de lidar-se com o conflito }\end{array}$ \\
\hline
\end{tabular}


tante corriqueira nos serviços de saúde. Muitos outros exemplos poderiam ser lembrados.

\section{Cenário}

Um centro de saúde hipotético (há inúmeras variações em torno da caracterização apresentada a seguir).

\section{Conflito}

Médicos com reclamações freqüentes, agressões verbais e má vontade com os auxiliares de enfermagem, em um centro de saúde, quando estes pedem que eles atendam "só" mais um paciente "de última hora", quando a cota de atendimento ou a jornada de trabalho do médico já chegaram ao fim".

\section{Utilização da matriz para análise}

\section{- Coluna 1}

O conflito descrito acima.

\section{- Coluna 2}

(a) Os atores envolvidos diretamente na situação conflituosa: os médicos, os auxiliares de enfermagem, o pessoal da recepção, o gerente da unidade, os pacientes.

(b) A apreciação que os atores envolvidos fazem da situação conflituosa: os médicos sentem-se pressionados, "explorados" por pedidos que chegam sempre fora de hora (ou bem na hora de ir embora...), sentem-se angustiados porque precisam sair correndo, pois têm outro(s) emprego(s), mesmo porque " S Secretaria de Saúde paga tão pouco...”; os auxiliares de enfermagem se estressam todos os dias, pressionados, de um lado, pelos usuários que eles vêem que estão precisando de ajuda e, por outro, pelos médicos que sempre se irritam e dificultam o acesso como se estivessem fazendo um favor para eles (auxiliares); além do mais, os médicos não cumprem o horário, enquanto os auxiliares têm que estar toda a jornada no centro de saúde. Avaliam, também, que os médicos, com um pouquinho mais de boa vontade, poderiam facilitar muito a vida de todos; o pessoal da recepção se angustia diante das demandas das pessoas que procuram atendimento, sabendo de antemão o quão difícil será “implorar" por mais um atendimento para o médico por intermédio dos auxiliares de enfermagem tão estressados; o gerente (em geral uma enfermeira), que vê esse conflito repetirse quase cotidianamente, sente-se irritado por- que não consegue "negociar" ou impor mesmo uma outra postura para o médico e impotente "porque as coisas na Secretaria sempre foram assim, e sempre que algum gerente resolveu enfrentar os médicos nesta questão de horário se deu mal"; por fim, o usuário que está vivendo a necessidade de atendimento e tem que esbarrar com a má vontade do auxiliar e do pessoal da recepção, que sempre colocam alguma dificuldade e sabem que ele, o usuário, terá que sair, por conta própria, atrás de atendimento em outro lugar, além de já saber que novas humilhações e dificuldades lhe esperam nas filas do pronto-socorro que inevitavelmente terá que demandar.

(c) Como "jogam" os atores na situação conflituosa: os médicos fazem ameaças veladas (ou abertas), dificultam o acesso, de toda as formas possíveis, evitando criar "precedentes" de tolerância, "para não acostumar mal o pessoal”. O enfrentamento nunca é direto com o paciente. Cede de cara feia (ou se recusa a atender, algumas vezes) quando o pedido é feito diretamente pela gerente; os auxiliares de saúde jogam em duas "frentes": são os mais duros possíveis com os pacientes, dizendo que não podem fazer nada porque as cotas de atendimento já estão esgotadas, mas sempre tentam um jogo de "sedução" com os médicos (nunca de enfrentamento, como, no íntimo, imaginam que seria justo fazer), tentando sensibilizá-los para uma ou outra situação que avaliam como justificado o pedido do "atendimento extra". Duplo estresse sempre. O pessoal da recepção faz o mesmo jogo dos auxiliares: como regra geral, joga "duro" com os usuários, fazendo o jogo do “não", mas tenta a "sedução" dos auxiliares para conseguir a vaga junto ao médico em situações que avalia como justificadas. De qualquer forma, tanto os auxiliares como o pessoal da recepção estão sempre em situação de tensão, em que devem avaliar os riscos de cada opção, em cada situação concreta; o jogo do gerente é o da omissão na maioria das vezes, deixando que as coisas se "resolvam" entre médicos e pessoal de enfermagem. Às vezes, interfere em situações que o conflito fica muito ruidoso, em particular quando o usuário "tenta fazer valer seus direitos” e é mais brigão; o usuário joga fazendo pressão sobre o pessoal da recepção, mas raramente expondo sua insatisfação diretamente ao médico. Uma forma de jogar pode ser levar sua queixa ao conselho gestor local (quando existe) ou queixar-se com o gerente ou procurar a imprensa, quando conhece "os caminhos" para tal.

(d) Os recursos que os atores envolvidos na situação conflituosa controlam: todos os atores 
envolvidos controlam algum recurso para resolver a situação problemática, como defende Friedberg 7. Os médicos controlam o recurso estratégico: o saber nuclear que resulta no atendimento pretendido. Esse saber/poder está inserido na ESPESSURA, referido a instituídos que atravessam o centro de saúde, mas que não podem ser compreendidos integralmente nele ou só a partir dele. O poder médico se exerce no centro de saúde, mas se origina em uma trama de relações e em outras instituições/organizações que extrapolam o espaço singular no estabelecimento analisado 11, em particular a Instituição Médica. Os auxiliares de saúde e o pessoal da recepção controlam o fluxo do paciente, sua movimentação na unidade, fazendo a intermediação entre o paciente e o médico. Gerenciam, em parte, o acesso. O gerente controla o recurso de autoridade (legal/formal) para, em princípio, tanto negociar novas rotinas e fluxos com os funcionários, incluindo os médicos, como para impor, por exemplo, o cumprimento do horário pelo médico. Por fim, os usuários, como cidadãos, controlam tanto o recurso de pressão direta sobre o serviço (com sua presença física, cobrança e tensionamento da equipe) como podem "fazer valer seus direitos" nas instâncias formalmente existentes de controle social (conselho gestor local, Conselho Municipal de Saúde).

\section{- Coluna 3}

(a) Como se lida com o conflito atualmente: a primeira coisa que poderíamos dizer aqui é que, nesse exemplo hipotético, não há um espaço formal de gestão que consiga incluir esse tipo de conflito em sua agenda de análise e decisão. No caso que estamos apresentando (mas bastante comum na realidade dos nossos serviços), esses conflitos ocorrem, com muita freqüência, cotidianamente, sendo "resolvidos" caso a caso, numa intricada rede de relações, barganhas, disputas, tensionando brutalmente o cotidiano das equipes. Cada situação é tratada como uma situação singular, um fenômeno isolado, sem o reconhecimento das mediações que remetem a tensões constitutivas que se inscrevem na ESPESSURA. Vemos, então, atores "escravos das circunstâncias”, sem potência para, pelo menos, tentar construir, de forma mais solidária e intencional, estratégias de melhoria de seus cotidianos tão desgastantes.

\section{- Coluna 4}

(a) Novas possibilidades de trabalhar-se os conflitos: há, em princípio, pelo menos duas estra- tégias a serem trabalhadas. A primeira seria de enfrentamento ou de confronto com os médicos, conduzida pelo gerente a partir do seu lugar de autoridade e, se necessário, apoiado por outros lugares de autoridade legal/formal (a direção do Distrito Sanitário ou da Secretaria Municipal de Saúde), que resultaria em medidas como cobrança do cumprimento da carga horária contratada, novas formas de agendamento por horário, exigência do atendimento de "encaixes" de eventuais etc. A Instituição Burocrática enfrentando e tentando se impor à Instituição Médica. Uma outra estratégia seria a que comporia uma linha mais afeita à negociação. Por exemplo, a construção de um espaço público e compartilhado de gestão pela equipe, como uma reunião periódica, com pauta que consiga incluir a discussão do tema pelos atores envolvidos. Nessas reuniões, seria tentada a criação de uma nova contratualidade que conseguisse deixar as regras do jogo mais claras e definidas, no mínimo, aliviando a sobrecarga que representa a "negociação" de cada situação conflituosa, na base das relações interpessoais, entre atores com controle de recursos de poder muito diferenciados. Típica situação de poder compartilhado.

\section{Discussão}

A primeira impressão que temos, ao nos propormos discutir o exemplo apresentado, é o quanto não há assuntos simples na agenda do gerente de saúde. Mesmo uma situação aparentemente corriqueira e que, em princípio, poderia ser facilmente resolvida (médicos em conflito com pessoal de enfermagem, em função do acesso mais ou menos ampliado ao consultório), remete-nos ao que denominamos ESPESSURA: o conjunto de instituídos, de instituições que atravessam e se enfrentam no lugar singular, que é um centro de saúde, de uma intricada rede de poder e de inconciliáveis visões de distintos atores a partir de diferentes lugares que ocupam. SUPERFÍCIE e ESPESSURA se interpenetrando, não em uma relação do tipo causa-efeito ou de determinação de sentido único, da ESPESSURA para a SUPERFÍCIE, mas muito mais dinâmica, de deslocamentos, de deformações mútuas. Um instrumento formatado na lógica da "planilha de análise dos conflitos" que ora apresentamos como ferramenta gerencial, apropriada e operada por atores reais, em situação, teria o propósito de contribuir para a realização desse complexo e pretensioso movimento de (re)construir algumas relações que são muito completivas no cotidia- 
no da organização. Como já afirmamos antes, pensamos que essa proposta de planilha possa ser alterada, adaptada, conforme o contexto organizacional trabalhado.

A partir dessa pretensão, temos que tentar responder a pelo menos duas questões que nos parecem centrais: (1) "qual a potência autoanalítica de um coletivo, muito implicado com a situação conflituosa, para realizar o tipo de análise que expusemos no exemplo acima?"; (2) "qual a potência (governabilidade) desse mesmo coletivo para propor novos arranjos, novas contratualidades, novas regras do jogo que resultem em mudanças, para melhor, para o maior número possível de atores envolvidos?".

Em relação à primeira questão, podemos afirmar que, antes de tudo, é possível construir esse espaço auto-analítico nos coletivos dos serviços de saúde. Em princípio e como possibilidade, sim, mas não sem certas exigências ou cuidados - chamemo-los de pressupostos nem sempre levados em consideração. O primeiro pressuposto é a existência de ator(es) implicado(s) na situação conflituosa com suficiente poder e/ou autoridade para enunciar o conflito como problema e conseguir a constituição de um coletivo (de implicados) com motivação para colocá-lo em análise. Em princípio, e por atribuição própria do lugar que ocupa, o gerente seria o ator mais indicado para esse primeiro movimento. Mas poderiam ser os usuários que conseguissem uma ação mais articulada e orgânica, através do conselho gestor local, por exemplo. Ou poderia ser o pessoal de enfermagem e da recepção que, não suportando mais o desgaste do cotidiano, conseguisse trazer para a pauta da gestão o tema do conflito. Como pode ser visto, esse primeiro movimento (definição da situação problemática e constituição de um coletivo com disposição auto-analítica) já implica em atores, intencionalidades, ação, mas, principalmente, controle de algum recurso de poder para impor uma definição da situação como problemática. Não se deve desconsiderar, também, que atores externos à situação conflituosa podem estimular e propiciar o processo auto-analítico da equipe como, por exemplo, a própria direção da Secretaria Municipal de Saúde, que, detectando o problema de outro lugar (no Conselho Municipal de Saúde), tem uma percepção de sua abrangência e desencadeia estratégias do tipo capacitar os gerentes para lidar com os conflitos e os estimule a criar grupos auto-analíticos nas várias unidades. Um segundo pressuposto, uma vez que a situação tenha sido declarada e reconhecida como problemática, diz respeito à capacidade do grupo para desenvolver o proces- so auto-analítico: saber lidar com conceitos, saber reconhecer e enunciar elementos que compõem a ESPESSURA, mas, principalmente, suportar dizer e escutar o que normalmente não se diz e não se escuta nas organizações. A idéia de trabalhar espaços auto-analíticos traz, de alguma forma, a idéia de que seria possível falar sobre tudo, que seria possível criar espaços de comunicação ideal, em que todos comunicam sem barulho, sem pensamentos reservados, sem estratégia, numa situação de transparência social. Pavé (1981, apud Friedberg 7; p. 259) nos alerta para o fato de que " a vida das organizações e o governo dos homens não suportam a clareza total. Precisam também de sombra, de arranjos informais, ocultos e portanto instáveis". Todas essas questões nos fazem pensar sobre a capacidade dos gerentes dos serviços (e suas equipes) para conduzirem o processo, na medida em que eles próprios estão muito implicados na situação conflituosa, comprometidos com alianças, acertos e preferências que vão sendo construídos no cotidiano da unidade. Dessa maneira, não seria apenas uma questão de "capacitar" os gerentes para conduzir o processo, mas pensar no necessário distanciamento que ele teria que ter para permitir a construção de uma análise mais produtiva da situação conflituosa. Tais considerações nos imporiam a necessidade de " $a l$ guém de fora" (um supervisor ou um analista institucional, entre outras possibilidades) para apoiar o processo da equipe? A Secretaria $\mathrm{Mu}$ nicipal de Campinas vem tentando construir esse tipo de profissional "apoiador" desde o ano 2000. Esse tipo de necessidade, que de maneira alguma poderia ser considerada " $u m l u$ $x o$ ”, pode ser bancada pela maioria das secretarias de saúde hoje? Se a resposta fosse sim, haveria oferta suficiente de profissionais com esse tipo de formação? Para concluir essa indagação, é bom lembrar que há, na literatura, uma discussão muito interessante sobre as dificuldades de construção de grupos autônomos ou semi-autônomos, como já estudado em algumas experiências realizadas no mundo da indústria, em países escandinavos. Como lembra Friedberg 7 (p. 287): “essas experiências subestimavam as dificuldades que podiam sentir grupos operários em passar de um funcionamento onde o conjunto das relações de trabalho era de algum modo gerido de maneira constrangente pela tecnologia e/ou por imposições hierárquicas, para um outro funcionamento em que essas relações de trabalho deviam ser geridas diretamente por eles". Por tudo isso é que se pode dizer que será necessário estar atento para dificuldades importantes no processo de 
constituição de grupos auto-analíticos nos serviços.

Já com relação à segunda questão que estamos nos propondo examinar nesta discussão de encerramento do artigo, talvez ela possa começar a ser respondida com outras questões: por que uma situação, tão tensionadora e difícil para tantos atores, mantém-se ao longo do tempo? Por que os vários atores envolvidos na situação conflituosa, mesmo tendo controle sobre recursos importantes, não se mobilizam e se articulam para mudar o estado de coisas? A gerente é investida de autoridade formal para exigir o cumprimento do horário médico; os usuários têm, garantido por lei, direito de controle sobre os serviços; o pessoal de enfermagem controla fluxo e entrada de pacientes. Se bem observado o exemplo analisado, aparentemente haveria uma confluência de interesses entre os auxiliares de saúde, o pessoal da recepção, o gerente e particularmente os usuários no sentido de que o médico ficasse mais tempo na unidade (pelo menos para cumprir a carga horária contratada) e que atendesse mais pacientes. Essa seria uma solução que melhoraria, com toda a certeza, a vida da maioria das pessoas que circulam no centro de saúde. Por que prevalecem os interesses dos médicos e sua definição da situação? Enfim, por que não se transforma uma situação que, aparentemente, é desfavorável para todos? (afinal, mesmo o médico que acaba impondo, em boa medida, sua definição da situação também sofre com esse cotidiano).

Em discussões que fizemos com coletivos que viviam situações reais muito parecidas com a que estamos analisando, há um certo espanto dos participantes quando, ao usarem a "planilha de análise dos conflitos", constatam que se sentem presos em uma rede ou em uma armadilha que é, afinal, uma construção deles próprios, que eles confirmam com sua ação cotidiana! Não há nenhum vetor de poder ou de autoridade externo, ou de cima para baixo, que justifique totalmente a manutenção de uma situação tão desfavorável para tantos, mesmo que se considere que "não há organizações em que as transações entre os participantes não obedeçam a imposições exteriores e autoridades explícitas" 7 (p. 163). A rede, a malha de relações que os prende e restringe seus cotidianos, é construída no próprio serviço, no conjunto das relações que vão sendo tecidas entre as pessoas. A percepção da materialidade dessa rede, que captura os atores em suas malhas, faz lembrar a pergunta de Varela 12, ao interrogar-se como cerca de dez carcereiros conseguiram tomar conta de um pavilhão com mais de 1.600 detentos no já extinto Presídio do Carandiru: “como um grupo tão pequeno de homens sem armas consegue controlar um presídio daquele tamanho é um dos mistérios da cadeia. Talvez o maior" 12 (p. 111). Poder em rede, construído em uma complexa relação de atores que controlam múltiplos recursos, que vão se influenciando mutuamente, ação agindo sobre ação 13 , poderes periféricos e moleculares, uma maquinaria, um conjunto de relações que se disseminam por toda a estrutura social 14 , a ESPESSURA, uma malha que os retêm, como se tivesse uma existência própria, independente dos homens que a tecem.

Pensamos que a indagação que fazemos sobre a potência desses coletivos para transformarem a situação conflituosa que vivenciam, utilizando-se da "planilha de análise de conflitos" como ferramenta de análise - mero dispositivo apoiador da reflexão e, necessariamente, utilizado em um processo que se prolonga no tempo, fazendo aproximações sucessivas à situação problemática - não comporta uma resposta única e de certeza. A resposta sobre a capacidade do grupo de produzir formas autogestionárias e transformadoras será mais pessimista se privilegiarmos a idéia que haveria, na ESPESSURA, instituídos e atravessamentos, assimetria de poderes e interesses tão poderosos que, no limite, a mínima veleidade de mudança, no espaço singular de qualquer estabelecimento de saúde, estaria fadada ao fracasso, tanto em função de uma forte "determinação externa" dos fenômenos observados como do fato de os atores estarem enredados em uma malha de relações da qual seria impossível escapar (a mosca se debatendo na teia da aranha: quando mais tenta escapar, mais presa fica...), a menos que fossem a figura mítica do Barão de Münchhausen que se alça pelos cabelos quando sua carruagem fica presa em um atoleiro 15.

A resposta será mais otimista se adotarmos o ponto de vista de Friedberg 7 (p. 287), para quem "um grupo que nas suas condições de ação concreta, isto é, nos constrangimentos materiais e relacionais da sua situação, aprendeu a gerir e de algum modo a domesticar, em vez de os abafar, os conflitos, as tensões, as discussões e as relações de poder e de concorrência inseparáveis da sua existência e da sua ação enquanto grupo, adquiriu, por esse fato, uma capacidade cultural propriamente coletiva. Esta, permitir-lhe-á agir melhor e mais eficazmente que outros grupos que, por razões diversas, não adquiriram essa capacidade". Essa pode ser uma possibilidade.

Por tudo o que foi dito, pensamos, enfim, que a resposta para a pergunta que dá o título 
deste artigo - "se seria possível usar o conflito como matéria-prima para a gestão” - vai depender, fundamentalmente, da capacidade dos coletivos viabilizarem novos arranjos e contratualidades, sempre precários e contingentes, eles próprios disparadores de novos conflitos ou, para usar os conceitos que adotamos nessa análise, tornar observáveis, visíveis, abertos, os conflitos que ficam encobertos, rechaçados das pautas de decisão, perpetuando relações de injustiça e iniqüidade, parte do mal-estar da organização.

\section{Resumo}

O autor examina a possibilidade de tomar os conflitos corriqueiros na vida das organizações de saúde como objeto da gestão. Para tanto, propõe a utilização de uma "matriz de análise", com o objetivo de possibilitar aos atores envolvidos na situação conflituosa, sempre em situação auto-analítica, uma melhor compreensão da dinâmica dos conflitos. Abrir-se-iam, assim, novas possibilidades de contratualidade para a gestão do cotidiano da unidade, novas configurações nas relações entre os trabalhadores, inclusive a explicitação de conflitos encobertos que não conseguem acessar a arena decisória do serviço. O autor indica, também, as possíveis dificuldades para a adoção desse tipo de prática gerencial.

Conflito (Psicologia); Organizações; Gerência

\section{Referências}

1. Motta PR. Gestão contemporânea: a ciência e a arte de ser dirigente. 2a Ed. Rio de Janeiro: Record; 1998.

2. Hall RH. Organizações: estrutura e processos. Rio de Janeiro: Prentice Hall do Brasil; 1984.

3. Lukes S. Poder: uma visão radical. Brasília: Editora UnB; 1980.

4. Birnbaum P. Conflitos. In: Boudon R, organizador. Tratado de sociologia. Rio de Janeiro: Jorge Zahar Editor; 1995. p. 247-82.

5. Boudon R. Tratado de sociologia. Rio de Janeiro: Jorge Zahar Editor; 1995.

6. Matus C. Planificación, política y gobierno. Caracas: Fundación Altadir; 1987.

7. Friedberg E. O poder e a regra: dinâmicas da ação organizada. Lisboa: Instituto Piaget; 1993.

8. Merhy EE. Saúde: a cartografia do trabalho vivo. São Paulo: Editora Hucitec; 2002.

9. Lapassade G, Lourau R. Chaves da sociologia. Rio de Janeiro: Civilização Brasileira; 1972.

10. Lapassade G. Grupos, organizações e instituições. Rio de Janeiro: Francisco Alves; 1989.

11. Baremblitt G. Compêndio de análise institucional. Rio de Janeiro: Rosa dos Tempos; 1996.

12. Varella D. Estação Carandiru. São Paulo: Companhia das Letras; 1999.

13. Foucault M. O sujeito e o poder. In: Rabinow $\mathrm{P}$, Dreyfus H, organizadores. Uma trajetória filosófica: para além do estruturalismo e da hermenêutica. Rio de Janeiro: Forense Universitária; 1995. p. 231-49.

14. Foucault M. Microfísica do poder. Rio de Janeiro: Graal; 1979.

15. Lowy M. As aventuras de Karl Marx contra o Barão de Münchausen. 2a Ed. São Paulo: Busca Vida; 1987.

Recebido em 06/Abr/2004

Versão final reapresentada em 27/Ago/2004

Aprovado em 01/Out/2004 